\title{
EL ROMANCE ELEGÍACO DE LUIS DE MIRANDA, EN EL CONTEXTO DE LOS ROMANCES ESPAÑOLES DE LA ÉPOCA*
}

\author{
THE ROMANCE ELEGÍACO BY LUIS DE MIRANDA, \\ IN THE CONTEXT OF THE SPANISH ROMANCES OF THE PERIOD
}

María Inés Zaldívar Ovalle

Pontificia Universidad Católica de Chile. Santiago, Chile mizaldiv@uc.cl

Recibido: 25.03.2013. Aceptado: 15.11.2013.

Resumen: En esta aproximación investigativa acerca del Romance elegíaco de Luis de Miranda (1537), interesa el análisis del poema en relación con los romances españoles que circulaban de la época. Para ello se considerará al Romance elegíaco como una posible expresión de los romances viejos españoles, históricos, de tradición oral, siguiendo la línea de Alan Deyermond y Mercedes Díaz Roig (entre otros). Fuente bibliográfica primaria en esta ocasión es la reciente edición crítica del texto realizada por Silvia Tieffemberg (2012). Esta edición cuenta con una reproducción facsimilar, prólogo y notas que serán de gran utilidad para nuestros propósitos.

Palabras clave: Luis de Miranda, romances viejos españoles, violencia.

\begin{abstract}
In this investigative approach to the Elegiac Romance by Luis de Miranda (1537), it is of interest the analysis of the poem in relation to other Spanish romances that circulated during the period. The elegiac Romance will be considered as a possible expression of ancient historical Spanish romances orally transmitted according to the cannon established by Alan Deyermond and Mercedes Díaz Roig, among others. A primary bibliographic source used in this study corresponds to the recently

* El presente trabajo se enmarca dentro del proyecto de investigación "Mal trillada y peor sembrada tierra. En torno al Romance de Luis de Miranda" (UBA- CONICET, 176), a cargo de la profesora doctora Silvia Tieffemberg, en el cual participo como investigadora externa.
\end{abstract}


published text by Silvia Tieffemberg (2012). The aforementioned text contributes a facsimile reproduction, a prologue and notes that would be useful for our purposes.

Keywords: Luis de Miranda, ancient Spanish romances, violence.

\section{Romance, lengua vernácula y más}

Aabemos que la palabra romance da cuenta de la lengua vernácula, pues tal como se lee en Covarrubias: "Este nombre es genérico a la lengua toscana, a la francesa y a la española, por cuanto estas tres derivaron de la pureza de la lengua latina, la cual los romanos, como vencedores, introdujeron en estas provincias" (Covarrubias: 2006, 1415). Si buscando una actualización del vocablo acudimos al Diccionario de la RAE (2009), nos encontraremos con una serie de acepciones que resultan interesantes de mencionar. De las ocho que aparecen, las dos primeras aluden directamente a la definición de Covarrubias, de la tercera a la sexta se alude a lo literario: (3. "Novela o libro de caballerías, en prosa o en verso"; 4. "Combinación métrica de origen español que consiste en repetir al fin de todos los versos pares una misma asonancia y en no dar a los impares rima de ninguna especie"; 5. "Romance de versos octosílabos"; 6. "Composición poética escrita en romance”) y, finalmente la 7 y 8 se relacionan con conductas humanas: "Relación amorosa pasajera" y "Excusas, bachillerías. Venirle con romances”. Certificamos entonces que, de las ocho acepciones, sólo la cuarta y quinta definirían, según nuestros propósitos, la forma literaria que nos convoca ${ }^{1}$, pero podría resultar productivo no olvidar que en las últimas se alude directamente a una experiencia de amor poco perdurable y en la

${ }^{1}$ En el recomendable Estudio Preliminar de la edición del Romancero de Rodríguez-Puértolas puede leerse al respecto:

La palabra romance deriva del latín vulgar de romanice, esto es, "en lengua vernácula"; en los siglos XIII-XIV aparece como romanz o romançe para significar obra literaria en lengua vernácula, no en latín (así, en el Poema de Mío Cid, en el Libro de Apolonio, en Gonzalo de Berceo, en las Siete partidas, de Alfonso el Sabio, en el Libro de buen amor). Para la segunda mitad del siglo XV, romance ya significa lo mismo que hoy, y Romancero, por analogía con cancionero, surge, finalmente, para indicar una colección de romances o el conjunto de los romances castellanos o de otra comunidad específica" (1992: 5). 
utilización del lenguaje como una sutil manera de engañar a otros. De la misma manera sería interesante poner atención a lo que estipula Covarrubias para cerrar su definición, aquello de que "los romanos, como vencedores, introdujeron [la lengua latina] en estas provincias”, pues nuevamente se define el romance en relación a una conducta, en este caso a la represión, que difícilmente puede no ser violenta.

Ahora bien, la historia crítica ha determinado que a partir del siglo XV se denomina romance a un tipo de creación literaria española que recoge expresiones del siglo anterior (y quizá de antes), que combinan oralidad y escritura a través de una narración que puede ser de variados temas. Este cantar y contar denominado Romancero, tal como afirma Paloma Díaz Mas, "no es más que un tipo de poesía narrativa de origen medieval que existe o ha existido en prácticamente todas las culturas europeas y que se conoce bajo el nombre genérico de balada" (2008: 115), que primero se cantó, recitó, y memorizó, y más tarde se vertió sobre papel -casi siempre el menos costoso de la época- muchas veces disperso. Por otra parte también sabemos, tal como afirma Alan Deyermond, que la "tradición romanceril hispánica es poco común por su calidad, su amplia aceptación social, su larga vida y su influencia en otros géneros literarios" (255) y que, dentro del contexto europeo, es el "ejemplo supremo" del género.

Por otra parte, según Deyermond, los variados temas que recogen las letras de los romances europeos, podrían agruparse fundamentalmente en tres: "históricos (nacidos directamente al arrimo de un suceso histórico), épicos y literarios (procedentes de un cantar de gesta o de otra fuente ya elaborada literariamente, aunque versen sobre algún motivo con realidad histórica) y novelescos o de aventuras (a menudo vinculados a un inmenso repertorio internacional de leyendas y relatos emocionantes)" (Deyermond, 1980: 255). Según el autor, sólo es posible identificar alguna datación en el caso de los romances históricos debido a que, al ser creados por un propósito inmediato, casi siempre de índole política, puede suponerse que se compusieron, justamente, "al calor del hecho histórico a que se refieren" (255).

Así las cosas y llevando el agua a nuestro molino, esta afirmación se enlazaría muy directamente con la creación del Romance elegíaco de Luis de Miranda, puesto que citando directamente a Silvia Tieffemberg, "El horizonte socio-político de producción del poema dirige nuestra atención al 
Río de la Plata como espacio que se está conformando en interacción con el propio continente y con la metrópolis: esto es, el Río de la Plata en el contexto del Alto Perú y los levantamientos de los encomenderos" (2012: 11). Por su parte, Gladys María Lopreto afirma que la expedición de Pedro de Mendoza realizó un asentamiento en la costa occidental, como parte de un plan de penetración en el continente en busca del cerro de la plata. El primer asentamiento fue en Buenos Aires en 1536, y "desde el comienzo se perfiló el fracaso” (1994: 89). Al mismo tiempo, respaldándose en indicios textuales, Lopreto aventura una fecha de escritura del romance compartida también por Tieffemberg: "la parte más central y extensa sería de 1537" (89).

\title{
II. Romance elegíaco, camino a la península
}

\author{
Año de mill y quinientos \\ que de veinte se decía, \\ cuando fue la gran porfía \\ en Castilla, \\ sin quedar ciudad ni villa, \\ que a todas inficionó \\ por los malos, digo yo, \\ comuneros, \\ que los buenos caballeros \\ quedaron tan señalados \\ afinados y acendrados \\ como el oro. \\ Semejante al mal que lloro \\ cual fue la comunidad, \\ tuvimos otra, en verdad, \\ subsecuente, \\ en las partes del poniente, \\ en el Río de la Plata. \\ Conquista la más ingrata \\ a su señor, \\ desleal y sin temor, \\ enemiga de marido, \\ que manceba siempre ha sido \\ que no alabo, \\ cual los principios el cabo


aquesto ha tenido cierto, que seis maridos ha muerto la señora.

Múdenos tan triste suerte dando Dios un buen marido, sabio, fuerte y atrevido a la viuda.

Desde la Historia de la literatura argentina de Ricardo Rojas y bajo el capítulo "Primeras Crónicas del Plata", se menciona el Romance elegíaco como "octosílabos de pie quebrado, un tanto semejantes a los de Manrique, [que] forman esa canción donde trasciende la congoja de la ciudad destruida, la memoria del largo sitio, las hambres y dolores padecidos en la siniestra fundación" (Rojas, 1948: 92). Rojas destaca a Luis de Miranda como un esforzado clérigo que estuvo entre los fundadores de la región y que oficiaba "como los obispos de la edad media, eran prelados y guerreros" (92). Para el historiador este romance vendría a ser una especie de crónica versificada, pero llama la atención y es útil para nuestros propósitos rescatar esta otra afirmación: "Su fondo de verdad y de realismo, se acomoda muy bien, sin embargo, a la índole de los romances castizos” (97). De allí en adelante se ha escrito acerca de este texto destacando en un principio sólo su valor documental, e incluso descalificándolo como texto literario pero, más recientemente, se ha rescatado también su importancia literaria al considerarlo como uno de los textos que inaugura la creación poética de la nación ${ }^{2}$.

En la actualidad hay consenso en la crítica sobre los aportes que ha realizado Beatriz Curia en el análisis y contextualización del Romance, especialmente con la edición y estudio sobre el poema de Miranda (1987) ${ }^{3}$. Además del renovado y minucioso análisis que hace del texto en donde destaca y reivindica su fuerza expresiva como poema, lo contextualiza con

${ }^{2}$ El inicio del recorrido crítico tiene hitos inevitables tales como Enrique de Gandía; Ismael Moya y su extenso estudio sobre el romancero americano e hispánico (1941). Para mayor información ver texto de Silvia Tieffemberg (2012).

${ }^{3}$ El libro tiene por título: Múdenos tan triste suerte, que corresponde a un verso del poema. 
la Relación de Gregorio Acosta (c. 1573), la Argentina de Martín del Barco Centenera (1602), los Comentarios (1545) de Alvar Núñez Cabeza de Vaca, la exposición de Pero Hernández de 1545 y la única carta conservada del propio Luis de Miranda, del 25 de marzo de $1545^{4}$. Además Curia tiene conciencia de que "El valor documental del poema residía, según creo, en la denuncia política que encierran sus versos" (23).

Otra relación establecida por la crítica contemporánea de la cual es preciso hacerse cargo, y que se desprende de la referencia que hace el Romance elegíaco a la Guerra de las Comunidades de Castilla entre los versos 1 y 12, es la vinculación con otro texto peninsular. Sofía Carrizo Rueda (1992 y 2005) hace la conexión entre el Romance de Miranda y el poema de Juan Del Encina conocido como las Coplas sobre el años de quinientos y veynte y uno, una composición menor que fue recogida al final de un manuscrito del Viaje a Jerusalem. El texto de Encina cuenta del levantamiento de los comuneros castellanos, y de la feroz hambruna que Castilla sufre durante ese año 1521. En un tono aleccionador, moralizante, y utilizando el retrato del mundo al revés, en el texto se establece que el hambre sufrida es un castigo divino por el levantamiento de los comuneros frente a la autoridad imperial. Tal actitud se lee como una deslealtad de éstos frente al emperador Carlos V y por lo tanto frente a Dios. En este mundo al revés se llega a la antropofagia, incluso profanando lazos de sangre, debido a que el esforzado trabajo de la tierra no produce frutos aunque los hombres trabajen como animales. Es así como Carrizo Rueda establece una serie de coincidencias entre ambos textos que se manifiestan tanto en la sustancia del contenido como en el ordenamiento. Estas son: la hambruna como castigo divino frente a la deslealtad; la antropofagia como práctica de sobrevivencia; la presencia de hechos y situaciones de la vida cotidiana; la presencia de la imagen de la mujer como una metáfora con particulares connotaciones que Miranda reúne en la viuda terrible que necesita marido que la enderece, y que en Encina aparece dispersa entre los comuneros y la tierra.

${ }^{4}$ El texto de Silvia Tieffemberg (2012), citando sus palabras, justamente "propone el estudio del poema de Miranda desde esa misma carta, considerada su contexto documental inmediato; y desde su contexto documental mediato: la Relación dirigida a Juan de Ovando, presidente del Real Consejo de Indias, en 1569 por Francisco Ortiz de Vergara, al final de la cual se encuentra copiado el poema”. 
Por otra parte, Elena Calderón de Cuervo, a partir de una breve y certera definición de romance ("forma estrófica, brevedad y fragmentarismo, oralidad y tradicionalidad" (2000: 203) plantea que, atendiendo a la clasificación de Deyermond, el Romance de Miranda debería ser estudiado dentro del corpus del Romancero hispanoamericano, e incluso: "podríamos incorporar el texto al grupo de romances históricos, aquellos nacidos directamente al arrimo del suceso histórico al que se refieren y que tienen implícito un propósito inmediato político y propagandístico" (205). Y como se sabe, es precisamente al calor de estos hechos históricos, sociopolíticos, constituidos por la sufrida y dificultosa expedición de Pedro de Miranda con el propósito de la conquista y asentamiento en el territorio rioplatense a partir de 1536, que se gesta este poema que habla de traición, guerra, hambre, canibalismo y muerte.

Ahora bien, atendiendo todo lo dicho anteriormente y utilizando las palabras de Ricardo Rojas en el sentido de que este texto posee "la índole de los romances castizos", surge la pregunta que estructura la presente reflexión: ¿podría afirmarse que este conjunto de ciento treinta y seis versos octosílabos (con pie quebrado), compuesto en una fecha próxima a los hechos (tiempo de la conquista y asentamiento español en la región del Plata), por el clérigo Luis de Miranda es un romance reconocible en el marco de la tradición de los viejos romances españoles de tradición oral?

\section{El romance histórico español y el relato de la violencia ${ }^{5}$}

Basándose en el Catálogo General del romancero elaborado por el seminario Menéndez Pidal, Mercedes Díaz Roig clasifica el romancero viejo en romances históricos noticieros y romances de invención y, dentro de los históricos que son los que nos competen en este momento, subdivide en fronterizos, históricos-varios e históricos-épicos. De estos tres últimos, por esta vez -puesto que a nuestro entender son los que mejor calzan con el perfil del Romance elegíaco- nos circunscribiremos a considerar como referencia los treinta y siete romances históricos noticieros ya sea fronterizos

${ }^{5}$ Todas las presentes versiones de los romances han sido tomadas de Mercedes Díaz Roig (2007). 
(18) o históricos varios (los 19 restantes). Y, como no es posible entrar a un análisis de cada uno, interesará ver, grosso modo, cuáles son los temas más recurrentes que tocan estos romances. Una primera lectura nos permite afirmar que la mayoría tiene como protagonistas tanto a personas -hombres y mujeres, nobles y villanos- como a lugares de la Península Ibérica y a sucesos que son identificables que son, de alguna manera, parte de la historia de una época determinada. Esta época podría circunscribirse, fundamentalmente, por la comprendida entre los siglos XIII al XV, en especial bajo la Corona de Castilla y la soberanía tanto de Pedro I el Cruel (1350-1366) y Enrique II (1367-1379) ${ }^{6}$, como la de Juan II quien reinó entre 1406 y 1454 . Una segunda lectura permite identificar a la mayoría de estos romances con hechos de violencia. En el grupo de los fronterizos esta es de tipo bélica, como es de suponer. Haciendo alarde de valentía y destreza -dependiendo de la pertenencia a un bando u otro-, moros y cristianos se desafían, se enfrentan, se cercan, se atacan, se matan; aunque algunas veces, en ambos bandos, suele asomarse alguno que traiciona a los de su grupo. Por lo tanto, la traición y su consecuente venganza o ajusticiamiento son también otro de los temas recurrentes.

Para ejemplificar la temática de los romances fronterizos leamos primero dos versiones que tocan el mismo asunto: el cerco a una ciudad, Baeza. El Romance del cerco de Baeza es el más antiguo de todos los fronterizos. Argote de Molina lo recopiló en su libro Nobleza de Andalucía (Sevilla, 1588), y es el único conservado del siglo XIV. El hecho histórico que subyace es el cerco que sufrió Baeza por las tropas del caudillo moro Audalla Mir, ayudado por las fuerzas del rey don Pedro el Cruel, en contra de don Enrique II, que en ese tiempo gobernaba la ciudad. Por razones de enemistad política don Pedro ayudó al rey granadino a poner cerco a la ciudad en 1368. Según Díaz Roig esto ha sido posible de certificar debido a que nombra a Pedro I con el apodo de "el traidor de Pero Gil", nombre dado por su hermano Enrique, que poco tiempo después pasó al olvido (2007: 85). El breve texto es el siguiente:

${ }^{6}$ Luchas por el poder entre ambos monarcas. 
Cercada tiene a Baeza - ese arráez ${ }^{7}$ Andalla Mir $^{8}$, con ochenta mil peones, - caballeros cinco mil. Con él va ese traidor, - el traidor de Pero Gil. Por la puerta de Bedmar - la empieza a combatir; ponen escalas al muro, - comiénzanle a conquerir; ganada tiene una torre, - no le pueden resistir, cuando de la de Calonge - escuderos vi salir. Ruy Fernández va delante, - aquese caudillo ardil ${ }^{9}$, arremete con Andalla, - comienza de le ferir, cortado le ha la cabeza, - los demás dan a fuir.

El mismo tema ${ }^{10}$, la misma ciudad, pero casi cuarenta años más tarde y desde el otro bando, es el romance Moricos, los mis moricos. Este se refiere al sitio de Baeza de 1407, bajo el reinado de Juan II, aunque según Díaz Roig - recogiendo la opinión de Lafuente (1845)-, la versión no parece ser contemporánea al hecho histórico debido a ciertos anacronismos.

Quisiera destacar también dentro del grupo de los romances fronterizos el conocido y estudiado "Romance de Amenábar" que, aunque no hay ninguna comprobación de que así sea, podría referirse al año 1431, cuando un príncipe árabe llamado Abenalmao ofrece sus servicios al rey Juan II para obtener el gobierno de Granada. Según Menéndez Pidal el romance se referiría específicamente al 27 de julio, cuando Juan II emprendió la conquista y mira la bella ciudad situado al pie de la sierra de Elvira, desde donde ésta se divisa. Cito los últimos versos:

Allí habló el rey don Juan, - bien oiréis lo que decía:

-Si tú quisieses, Granada, - contigo me casaría;

daréte en arras y dote - a Córdoba y a Sevilla.

-Casada soy, rey don Juan, - casada soy, que no viuda;

el moro que a mí me tiene - muy grande bien me quería.

Verídico el hecho o no, lo que sí podemos afirmar es que este romance tiene como base un tema de origen árabe, "el ver a la ciudad como una

${ }^{7}$ Caudillo árabe.

${ }^{8}$ En algunas versiones se moderniza como Alvaraez Abdalamir.

${ }^{9}$ Astuto.

${ }^{10}$ El Romance del moro de Antequera es otro texto que relata el cerco y la toma de una ciudad. Cfr. 89-90. 
mujer que se quiere conquistar" (Díaz Roig, 2007: 93), y este tipo de metaforización se relaciona directamente con el Romance elegíaco de Miranda.

En los romances históricos de temas varios, la violencia sigue siendo una constante. En ellos ésta tiene que ver más bien con guerras entre reinos cristianos, como la de Juan Alberto de Navarra que es vencido por Fernando el Católico de Aragón (1513-1515). En el Romance del Rey don Juan de Navarra (Díaz Roig, 2007: 113) en un ambiente sombrío, el monarca se lamenta por la derrota y aparece la Fortuna personalizada en una joven doncella que busca su compañía, sin resultados.

Los aires andan contrarios, - el sol eclipse hacía, la luna perdió su lumbre, - el norte no parecía, cuando el triste rey don Juan - en la su cama yacía, cercado de pensamientos, - que valer no se podía.

-¿Quién eres tú, la doncella? - dímelo por cortesía.

-A mí me llaman Fortuna, - que busco tu compañía.

-iFortuna, cuánto me sigues, - por la gran desdicha mía, apartado de los míos, - de los que yo más quería!

Se cantan también las luchas intestinas de poder, mezcladas con crímenes pasionales, que se resuelven en asesinatos, como en el caso del "Romance de doña Isabel de Liar" y del "Romance de la venganza de doña Isabel". Ambos textos se refieren a doña Inés de Castro, esposa del infante Pedro de Portugal, quien fuera asesinada en 1355 a causa de intrigas palaciegas ${ }^{11}$. En el primero se describe el prendimiento, los lamentos y la muerte de doña Isabel, amante cautiva del rey y madre de sus hijos, a manos de don Rodrigo de Chavela, primo de la reina esposa. Dicen así los últimos versos:

Sale de la confesión - con sus tres hijos delante: el uno dos años tiene, - el otro para ellos vae, y el otro que era de teta, - dándole sale a mamare; toda cubierta de negro, - lástima es de la mirare.

${ }^{11}$ En estos romances se cambia el nombre, no sólo el de Inés por Isabel, sino también el del príncipe (que en realidad era el rey don Juan Manuel) y el de los agresores que en la realidad fueron. Menéndez Pelayo no se explica este cambio de nombres pues el hecho era de público conocimiento (cfr. Díaz Roig, 2007). 
-Adiós, adiós, hijos míos, - hoy os quedaréis sin madre; caballeros de alta sangre, - por mis hijos queráis mirare, que al fin son hijos de rey, - aunque son de baja madre. Tiéndenla en un repostero - para haberla de degollare; así murió esta señora, - sin merecer ningún mal.

En el segundo el rey don Juan Manuel vuelve a Portugal después de vencer moros en Ceuta y Tanjar y, en vez de ir donde la reina su mujer en Lisboa, se dirige a Coimbra a ver a su amiga Isabel, la madre de sus hijos. Esta ya había sido asesinada y enterrada. El rey entonces, de singular manera, procede a vengar la muerte de Isabel matando a don Rodrigo, y asegurándose que la descendencia tenida con ella sea la que lo suceda en el trono:

\footnotetext{
Vase a la sepultura - do doña Isabel está, hecho la había sacar de ella - y luego desenterrar. Encima de un rico estrado - allí la mandó sentar, púsole daga en la mano - y a don Rodrigo delante. El rey le tiene la mano, - de puñaladas le da. -Aquí os vengaréis, señora, - de quien os hizo este mal. Luego se casó con ella, - así muerta como está, porque pudiesen sus hijos - a sus reinos heredar.
}

Prisión y muerte por encargo debido a los celos de la esposa frente a la fértil amante, quien se encuentra sola con tres niños de dos y un año, más otro recién nacido, y sin familia a quien pedir ayuda ni venganza. Venganza que supone la exhumación de la muerta que había sido degollada, la utilización de su cuerpo para asesinar al hechor, y el matrimonio post mortem, dan cuenta de una violencia calculada, refinada y brutal.

La presencia de la mujer, y encadenado a ella el tema del honor, se reitera en estos romances, constituyéndose en figura principal a veces como culpable (tal es el caso de doña María de Padilla (Díaz Roig, 2007: 129131), injustamente según algunas versiones históricas), y más generalmente como víctima de violencia y hasta de homicidio. Es el caso también en "Muerte de la reina Blanca” (Díaz Roig, 2007: 134-135) que relata con ternura y crudeza la muerte de Blanca de Borbón, ejecutada por orden del rey y para favorecer a María de Padilla. El hecho histórico a que se refiere sería la ejecución de la joven reina por orden de su marido Pedro el Cruel 
en 1361, aunque algunos historiadores piensan que ésta habría fallecido de muerte natural. De igual manera, la mención explícita que hace el rey al iniciar el romance sobre María de Padilla sería mera invención. El romance que presenta con belleza el contraste entre la brutalidad de la orden real y la resignación y dulzura de la joven doña María, finaliza así:

Sus lágrimas y gemidos - al macero enterneció, con la voz flaca temblando - esto a decir comenzó:

-iOh Francia, mi noble tierra! - -iOh Mi sangre de Borbón!

Hoy cumplo diecisiete años - en los dieciocho voy.

El rey no me ha conocido, - con las vírgenes me voy.

Castilla ¿di qué te hice? - no te hice traición, las coronas que me diste - de sangre y suspiros son, mas otra tendré en el cielo, - será de más valor. Y dichas estas palabras - el macero la hirió, Los sesos de la cabeza - por la sala les sembró.

Otro tanto puede apreciarse en el "Romance de la duquesa Berganza", que remite a la muerte de la esposa, que según algunos críticos sería María Téllez a manos del infante don Juan de Portugal, y otros a doña Leonor de Mendoza, esposa de don Jaime, duque de Braganza muerta en $1512^{12}$. En este romance se describe la evolución de los hechos que van, desde una violenta discusión de la pareja, hasta la muerte de la esposa:

-Traidora sois, la duquesa, - traidora, fementida.

La duquesa muy turbada, - de esta suerte respondía:

-No soy yo traidora, el duque, - ni en mi linaje lo había, nunca salieron traidores - de la casa do venía.

Viéndose en este aprieto, - a grandes voces decía:

-Socorredme, caballeros, - los que truje de Castilla.

Quiso la desdicha suya - que ninguno parecía, que todos son portugueses - cuantos en la sala había.

Parece interesante destacar también, tanto en este romance como en el anterior, la indefensión de las mujeres que, a causa de su matrimonio, son "extranjeras" en el lugar que habitan.

${ }^{12}$ Refrendando a Mercedes Díaz Roig, Wolf estaría de acuerdo con lo primero y Meléndez Pelayo con lo segundo. 
En el "Romance de la mujer del duque de Guymaraes de Portugal" se narra cómo estos ajusticiamientos sumarios provocan dramas familiares donde nuevamente la mujer -aunque no sea la víctima directa- siempre saca la peor parte. En este caso: marido asesinado, ella prisionera junto a su hija, y los tres hijos varones muertos o desaparecidos y, lo peor según la duquesa, la pérdida irremediable del honor que no tiene esperanzas de ser vengado:
No lloro tanto su muerte, - como verlo deshonrado con un pregón que decía - lo por él nunca pensado. Murió por culpas ajenas, - injustamente juzgado; él ganó por ello gloria, - yo para siempre cuidado y en prisiones muy esquivas - en que vos me habéis echado, con una hija que tengo, - que otro bien no me ha quedado; que tres hijos que tenía - habéismelos apartado. El uno es muerto en Castilla, - el otro, desheredado, el otro tiene su ama, - no espero verle criado, por el cual pueden decir - inocente desdichado; y pido de vos enmienda, - rey, señor, primo y hermano, a la justicia de Dios - de hecho tan mal mirado, por verme a mí con venganza - y a él sin culpa, culpado.

Del ciclo de romances sobre el reinado de Pedro el Cruel hay otros dos textos que quisiera destacar: "Entre las gentes se suena" (127) que, cambiando el tono al utilizar humor e ingenio, habla de traiciones de alcoba e hijos ilegítimos, esta vez de la reina, doña Blanca, esposa de don Pedro, con su hermano don Fadrique de Castilla. Y aunque no se sabe con exactitud si hubo amores entre ambos, lo que queda claro en el texto es la simpatía que el pueblo tiene hacia la reina asesinada. Y, el segundo, es "Romance del rey don Pedro el Cruel” (132), texto que muestra al monarca en una escena de caza, "Por los campos de Jerez". Cargado de un ambiente lúgubre "vio bajar un bulto negro" y, junto a este funesto presagio aparece "llorando y gimiendo" un niño pastor. A través de este pastorcillo anónimo que "a grandes voces decía: -Morirás, el rey don Pedro”, se le enrostra al monarca "que mataste sin justicia - los mejores de tu reino", y detallando la injusticia y la violencia de su actuar, lo acusa: "mataste tu propio hermano, - el Maestre, sin consejo, / y desterraste a tu madre, - a Dios darás cuenta de ello. / Tienes presa a doña Blanca, - enojaste a Dios por ello”, y le predice 
un triste final: "serán malas las tus hijas - por tu culpa y mal gobierno, / y tu hermano don Enrique - te habrá de heredar el reino, / morirás a puñaladas, - tu casa será el infierno". Finalmente, "Todo esto recontado, - despareció el bulto negro" (132-133).

Dos romances que relatan conflictos entre varones son el "Romance del rey don Fernando" y el "Romance del prior de Sant Juan". El primero que tiene una factura de crónica-romance, se basa en la narración de la muerte de Fernando IV el Emplazado (c. 1285-1312) ${ }^{13}$. El otro es el "Romance del prior de Sant Juan", que da cuenta de la rebelión en 1328 del Prior Fernán Rodríguez de Valbuena, en Consuegra y su posterior reconciliación con Alfonso $\mathrm{XI}^{14}$. Y, por último, para cerrar este breve recuento temático, otros dos romances del reinado de Juan II son "Romance de los infantes de Aragón", considerado el más antiguo romance del que se posee la música y que se refiere a la derrota de Juan II ante Alburquerque en $1430 \mathrm{y}$, el otro, el "Romance del duque de Arjona", que canta y cuenta el castigo real a un noble debido a su mala conducta con las damas, aunque el hecho histórico que subyace conduce más bien al encarcelamiento del susodicho en 1429 por las sospechas de traición que de él tiene Juan II (139).

En los romances históricos se entremezcla la historia personal con la colectiva y todo enlazado se convierte en noticia para ser difundida y comentada. Desde batallas pasando por ajusticiamientos, destierros, traiciones, hasta adulterios, engaños y venganzas, en boca del pueblo van conformando un relato de cariz provocador, que toma partido, y que busca el impacto y la atención del oyente. Para ello las descripciones son vívidas y detalladas y se utilizan imágenes aprehensibles, de fácil llegada y retención en la memoria. Se canta y cuenta el triunfo y la derrota, la venganza, la traición y en algunos casos hasta le reconciliación entre individuos que generalmente por diversas formas de búsqueda del poder o de usurpación o defensa de privilegios, se convierten en enemigos. Como puede apreciarse entonces, sin mayores explicaciones, es un hecho en el cantar y contar de los romances históricos eso de que "manchas de honor se lavan con sangre". Lengua

\footnotetext{
${ }^{13}$ Se trata del hijo de Fernando III el Santo y María de Molina, y nieto de Alfonso $\mathrm{X}$ el Sabio.

${ }^{14} \mathrm{El}$ contexto histórico de esta situación está detenidamente relatado y analizado por Diego Catalán (1969).
} 
nueva y violencia antigua que se difunde como una noticia de crónica roja, y a propósito de esta afirmación, entonces, parece oportuno recordar aquí lo que se planteaba al inicio, eso de poner atención a lo que estipula Covarrubias para definir romance, aquello de que "los romanos, como vencedores, introdujeron [la lengua latina] en estas provincias" pues, no deja de ser cierto a estas alturas, que este tipo de texto, contado y luego escrito en la lengua vernácula, encierra una conducta, la de la relación, siempre violenta, entre vencedores y vencidos.

\section{Romance elegíaco, en el contexto de los romances viejos peninsulares, puntos de contacto}

Respondiendo a la pregunta acerca de la incorporación del Romance de Miranda dentro del marco de la tradición de los viejos romances españoles, nuestra respuesta es afirmativa aunque en su factura escritural no lo sea totalmente. (No es el propósito actual entrar en esta materia). Después de este recorrido, hemos llegado a la convicción de que es el "espíritu" del romance -más que la precisión métrica o estrófica- lo que cuenta, lo que en definitiva prevalece. $\mathrm{O}$, mejor dicho aún, parafraseando las palabras de María Cruz García de Enterría (1973), estamos en el caso de los romances viejos españoles frente a la utilización de una retórica menor al servicio de una retórica afectiva. Romance es comunicación popular, es la noticia no oficial que pretende ser difundida para provocar un impacto, una reacción; romance no es reflexión sobre el lenguaje, ésa es la que estamos haciendo nosotros siglos después.

Debido a la vinculación que la crítica ya ha establecido entre el Romance elegíaco de Luis de Miranda con Coplas sobre el años de quinientos y veynte y uno de Juan del Encina, se ha abierto un campo de estudio y reflexión que permite ampliar este horizonte discursivo hacia otros romances populares españoles. Este es el camino que he intentado emprender en este trabajo. Y es a partir de esta relación explícitamente trabajada y probada que hemos podido establecer una serie de semejanzas temáticas entre este texto con una parte importante del corpus conformado por los romances viejos castellanos de tradición oral. Resumiría estos puntos de contacto a través de las siguientes afirmaciones: 
-Coincidencia del Romance elegíaco con los romances viejos españoles en cuanto es un texto que tiene una base histórica puesto que, al decir de Alan Deyermond, ha nacido "directamente al arrimo de un suceso histórico”. Esta base histórica se materializa en la presencia de un territorio geográfico y la nominación de personajes identificables, "reales".

-Coincidencia en su difusión primera de tradición oral, que luego es fijada dentro de un corpus escrito que es el que llega a nuestros días. En este caso a través de un manuscrito que lo incluye entre otros textos, guardado en el Archivo de Indias. Este documento está fechado en 1560, se dirige a Juan de Ovando, y lleva la firma Francisco Ortiz.

-Coincidencia en cuanto es un texto noticioso, informativo, que da cuenta de un hecho histórico político y de índole violento.

-Coincidencia en cuanto este hecho histórico, político y violento tiene el carácter de una noticia de crónica roja en su impacto. El tema del canibalismo, en el caso del Romance elegíaco, tiene una relación analógica a otras situaciones de impacto social que poseen los romances españoles.

-Coincidencia en la formación de bandos o facciones dentro de un mismo ejército, y de enfrentamientos y traiciones dentro de él, que podría leerse como la presencia de buenos y malos caballeros. Estos ejércitos, a su vez, están enfrentados a una guerra externa "fronteriza" con otro enemigo, ya sea con los moros en la península, o con los indígenas en tierras de América.

-Coincidencia también en el protagonismo de la mujer como personaje, real o metafórico. Esta mujer aparece tanto violenta y desdeñosa (como es el caso del Romance elegíaco) o bien mayoritariamente violentada (como en los romances históricos españoles).

-Coincidencia en la utilización del tema de origen árabe consistente en ver a la ciudad como una mujer que se quiere conquistar, que en el caso del Romance elegíaco resulta ser la: "Conquista la más ingrata/ a su señor,/ desleal y sin temor,/ enemiga de marido" (19-22), tanto así: "que seis maridos ha muerto / la señora" (27-28).

Para cerrar estas reflexiones quisiéramos plantear que aunque en esta ocasión nos interesó examinar la relación del Romance elegíaco con otros 
textos peninsulares de la época, es indispensable no perder de vista la amplitud de los puntos de contacto -y por lo tanto de atención- que se perfilan dentro de este campo de estudio a partir de este texto. Un certero mapeo de estas posibilidades de análisis es presentado por Tieffemberg en la introducción de su reciente edición crítica, ya que el horizonte sociopolítico de producción del poema no sólo orienta nuestra atención hacia el Río de la Plata, el Río en el contexto del Alto Perú, la conquista y asentamiento, y los levantamientos de los encomenderos, sino también hacia una serie de otros importantes aspectos a considerar tales como:

la circulación de las Leyes Nuevas en América y la modificación de las políticas sobre los indígenas en la región; los comuneros, entendidos como las resignificaciones regionales de un conflicto metropolitano; las huestes y la instrumentalización de las guerras de botín. Es decir, nos encontramos en un momento en que la región se articula en -al menosdos espacios de fronteras lábiles donde el trueque debe ser dimensionado en la interacción con los grupos indígenas vernáculos y los mapas físicos se tensionan con los mapas culturales (Tieffemberg, 2012: 11).

Por otra parte, en el campo discursivo, la producción escritural del Romance elegíaco se conecta, no sólo con Juan del Encina y los Romances viejos españoles, sino también y como afirma la autora, con: "Flavio Josefo y la circulación del tópico del cerco de Jerusalén en el Río de la Plata, a Joan de Osorio y el peso del castigo divino; a la conquista feminizada: la estéril, la viuda, la manceba; a la muerte por hambre o "la rabiosa"; a la antropofagia y al cuerpo como saqueo" (11).

\section{Referencias}

Calderón de Cuervo, E. (2000). Algunas notas sobre la poética del género popular a propósito del Romance elegíaco de Fray Luis de Miranda. Revista de Literaturas Modernas, 30, 199-210. Recuperado de http://bdigital.uncu. edu.ar/2680

Carrizo Rueda, S. (1992). Juan del Encina: Una importante presencia en la primera fundación de Buenos Aires. En Actas del III Congreso Argentino de Hispanistas 'España en América y América en España' (pp. 393-399). Buenos Aires: Instituto de Filología y Literaturas Hispánicas Dr. Amado Alonso. 
(2005). El descubrimiento de una nueva fuente del romance de Luis de Miranda y su filiación con la poesía española del siglo XVI. En El humanismo indiano. Letras coloniales hispanoamericanas en el Cono Sur. Actas de las Jornadas de Literatura Colonial del Cono Sur, 2001 (pp. 325-332). Buenos Aires: Universidad Católica Argentina.

Catalán, D. (1969). Siete siglos de romancero. Madrid: Gredos.

Covarrubias Horozco, S. de. (2006). Tesoro de la lengua castellana o española. Edición integral e ilustrada de Ignacio Arellano y Rafael Zafra. Madrid: Universidad de Navarra. Iberoamericana. Vervuert. Real Academia Española. Centro para la edición de Clásicos Españoles.

Curia, B. (1987). Múdenos tan triste suerte. Sobre el Romance de Luis de Miranda. Mendoza: FFL-CADEI.

Deyermond, A. (1980). El romancero. En Rico, F. (ed.), Historia y crítica de la literatura española: Edad Media (pp. 255-264). Barcelona: Crítica.

Díaz Mas, P. (2008). El romancero, entre la tradición oral y la imprenta popular. Destiempos, 15, 115-129.

Díaz Roig, M. (2007). El romancero viejo. Madrid: Cátedra.

Diccionario de la Lengua Española. Vigésima segunda edición 2009. Madrid: Espasa Calpe. Recuperado de http://www.rae.es/rae.html

García de Enterría, M. C. (1973). Sociedad y literatura de cordel en el Barroco. Madrid: Taurus.

Lafuente y Alcántara, M. (1845). Historia de Granada. Comprendiendo la de sus cuatro provincias Almería, Jaén, Granada y Málaga, desde remotos tiempos hasta nuestros días. Tomo III. Madrid: Imprenta y librería de Sans.

Lopreto, G. M. (1994). El Romance de Luis de Miranda. Aportes para su ubicación cronológica y genérica. En Actas del Coloquio Internacional Letras Coloniales Hispanoamericanas Literatura y cultura en el mundo colonial hispanoamericano (pp. 89-99). Buenos Aires: Asociación Amigos de la Literatura Latinoamericana.

Moya, I. (1941). Romancero. Tomo I. Buenos Aires: Facultad de Filosofía y Letras de la Universidad de Buenos Aires. Imprenta de la Universidad.

Rodríguez-Puértolas, J. (1992). Romancero. Madrid: Akal.

Rojas, R. (1948). Historia de la literatura argentina. Segunda parte Los Coloniales I. Buenos Aires: Losada.

Tieffemberg, S. (2012). El Romance de Luis de Miranda (Edición, edición facsimilar, prólogo y notas). Buenos Aires: Editorial de la Facultad de Filosofía y Letras de la Universidad de Buenos Aires. 